\title{
Characteristics of Artificial Immunogens Containing Peptide Mimotopes of HIV-1 Epitopes Recognized by Monoclonal Antibodies 2F5 and 2G12 N. S. Shcherbakova ${ }^{1}$ A. N. Chikaev², A. P. Rudometov ${ }^{1}$, D. N. Shcherbakov', A. A. Il'ichev' ${ }^{1}$, and L. I. Karpenko ${ }^{1}$
}

Translated from Byulleten'Eksperimental'noi Biologii i Meditsiny, Vol. 167, No. 2, pp. 213-217, February, 2019 Original article submitted September 27, 2018

\begin{abstract}
The paper describes construction of TBI-based recombinant proteins TBI-2F5 and TBI-2G12 that contain peptide mimotopes of HIV-1 epitopes recognized by broadly neutralizing antibodies $2 \mathrm{~F} 5$ and $2 \mathrm{G} 12$, respectively. The capacity of the immunogens to induce neutralizing antibodies was evaluated. The sera of BALB/c mice immunized with recombinant proteins TBI, TBI-2F5, and TBI-2G12 neutralized HIV-1 env-pseudoviruses. Moreover, pooled serum from mice immunized with TBI-2F5 and TBI-2G12 neutralized env-pseudoviruses of HIV-1 subtype B more effectively than individual sera.
\end{abstract}

Key Words: HIV-1; monoclonal antibodies $2 F 5$ and 2G12; HIV-1 immunogen; phage display

High risk posed by HIV requires the development of new techniques for prevention and treatment of HIV infection. Vaccine development is considered one of the most effective preventive approaches. The main challenge in designing vaccine against HIV is unusual biology of the virus that reproduces in cells of the host immune system and gradually destroys it. The virus is extremely variable and persists in a host as quasispecies, i.e. a set of different viral variants, which allows it escaping from the host immune system [2]. The discovery of broadly neutralizing antibodies that can neutralize a wide range of HIV-1 isolates inspired vaccine developers and encouraged the construction of immunogens that can induce these antibodies [8]. Serious challenge in immunogen construction is that most broadly neutralizing antibodies recognize conformational epitopes. The problem can be solved by using the phage display technique that allows selection of liner peptides that mimic conformational epitopes [12].

${ }^{1}$ State Research Center of Virology and Biotechnology Vector, Federal Service on Surveillance for Consumer Rights Protection and Human Well-Being (Rospotrebnadzor), Kol'tsovo, Novosibirsk region; ${ }^{2}$ Institute of Molecular and Cellular Biology, Siberian Division of the Russian Academy of Sciences, Novosibirsk, Russia. Address for correspondence: shherbakova_ns@vector.nsc.ru. N. S. Shcherbakova
At the Department of Bioengineering of the State Research Center of Virology and Biotechnology Vector, peptide mimotopes of $2 \mathrm{~F} 5$ and $2 \mathrm{G} 12$ epitopes of HIV-1 were selected from phage peptide library by biopanning. 2F5 binds the epitope in MPER region of HIV-1 glycoprotein gp41 [14], while 2G12 recognizes conformational mannose-rich epitope on the surface of gp120 [10]. TBI-2F5 and TBI-2G12 that include peptide imitators of HIV-1 epitopes recognized by $2 \mathrm{~F} 5$ and $2 \mathrm{G} 12$ were constructed on the basis of multiepitope immunogen TBI.

The aim of the study was to analyze the immunogenic properties of the anti-HIV-immunogens TBI-2F5 and TBI-2G12.

\section{MATERIALS AND METHODS}

Plasmids pTBI-2F5 and pTBI-2G12 were constructed by Bsp13I and ApaI restriction site-based cloning of synthesized oligonucleotides encoding the peptide mimotopes of 2F5 epitope (RDWSFDRWSLSEFWL) and 2G12 epitope (VGAFGSFYRLSVLQS) into plasmid pTBI [3].

Bacterial producers of recombinant proteins were constructed by transformation of $E$. coli JM103 with 
plasmids pTBI, pTBI-2F5, and pTBI-2G12. During cell expansion, the proteins were induced with nalidixic acid.

Recombinant proteins were purified by extraction from inclusion bodies in PBS containing $8 \mathrm{M}$ urea. The proteins were refolded by dialysis against PBS with subsequent chromatography on DEAE-cellulose [6]. Protein purity and homogeneity were verified by SDS-electrophoresis in 15\% PAAG.

Male BALB/c mice weighing 16-18 g (vivarium of State Research Center of Virology and Biotechnology Vector) were intraperitoneally immunized with the purified proteins TBI, TBI-2F5, and TBI-2G12 ( $20 \mu \mathrm{g}$ protein on days 0,14 , and 28 of the experiment with complete and incomplete Freund's adjuvant and without adjuvant, respectively); negative control group received saline. The animals were handled according to Regulations on Animals Experiments. The plan of the experiment was approved by Bioethical Committee of the State Research Center of Virology and Biotechnology Vector (Order No. 03, February 6, 2017). The sera were collected on day 35 .

Neutralization assay was based on env-pseudoviruses of the following HIV-1 subtypes B: QH0692.42; PVO.4 (obtained through NIH AIDS Research and Reference Reagent Program), and CRF63_02A1: pNov_1, pNov_2 and pNov_4 (produced at the State Research Center of Virology and Biotechnology Vector). Neutralization assay was performed as described previously [11]. $\mathrm{IC}_{50}$ and $95 \%$ confidence interval were calculated by using probit analysis (ProbitLin software). When analyzing the neutralizing properties of individual sera, the pseudovirus was incubated with single serum For evaluation of neutralizing properties of pooled sera, the pseudovirus was simultaneously incubated with two sera obtained form mice immunized with TBI-2F5 and TBI-2G12 immunogens.

\section{RESULTS}

Artificial polyepitope immunogen TBI that contains B-cell and T-helper HIV-1 epitopes to stimulate antibody response was used to construct immunogens that include pre-selected peptide mimotopes of 2F5- and 2G12-epitopes of HIV-1 [3] (Fig. 1).

The synthesized oligonucleotides encoding peptide mimotopes were cloned into pTBI instead of a part of TBI gene that encodes p17 peptide of HIV-1 (gag (99-317) (Fig. 1). The C-terminal epitope was substituted because p17 is a core virion protein and partial deletion of p17 gene is not critical for induction of protective HIV-1 antibodies. We obtained two plasmids (pTBI-2F5 and pTBI-2G12) containing the sequences of $2 \mathrm{~F} 5$ and $2 \mathrm{G} 12$ epitope mimotopes. After that, bacterial producers of TBI, TBI-2F5, and TBI$2 \mathrm{G} 12$ proteins were obtained by transformation of $E$. coli JM103 using constructed plasmids. The production of recombinant proteins was assessed by electrophoresis in $15 \%$ PAAG (Fig. 2).

$\mathrm{BALB} / \mathrm{c}$ mice were immunized with the purified proteins. We have previously demonstrated that sera of mice immunized with the TBI, TBI-2F5 and TBI-2G12 specifically bound protein TBI and peptide mimotopes in ELISA and native HIV-1 proteins in New LAV blot (Bio-Rad) [11]. Here, we evaluated the ability of immunized mouse serum to neutralize env-pseudoviruses of HIV-1 subtype B and recombinant CRF63 02A1.

First, we determined serum dilution that provides $50 \%$ neutralization of the pseudoviruses (Fig. 3).

Antibodies in the sera from mice immunized with original TBI protein better neutralized tier 2 subtype B QH0692.42 pseudovirus. However, the sera from

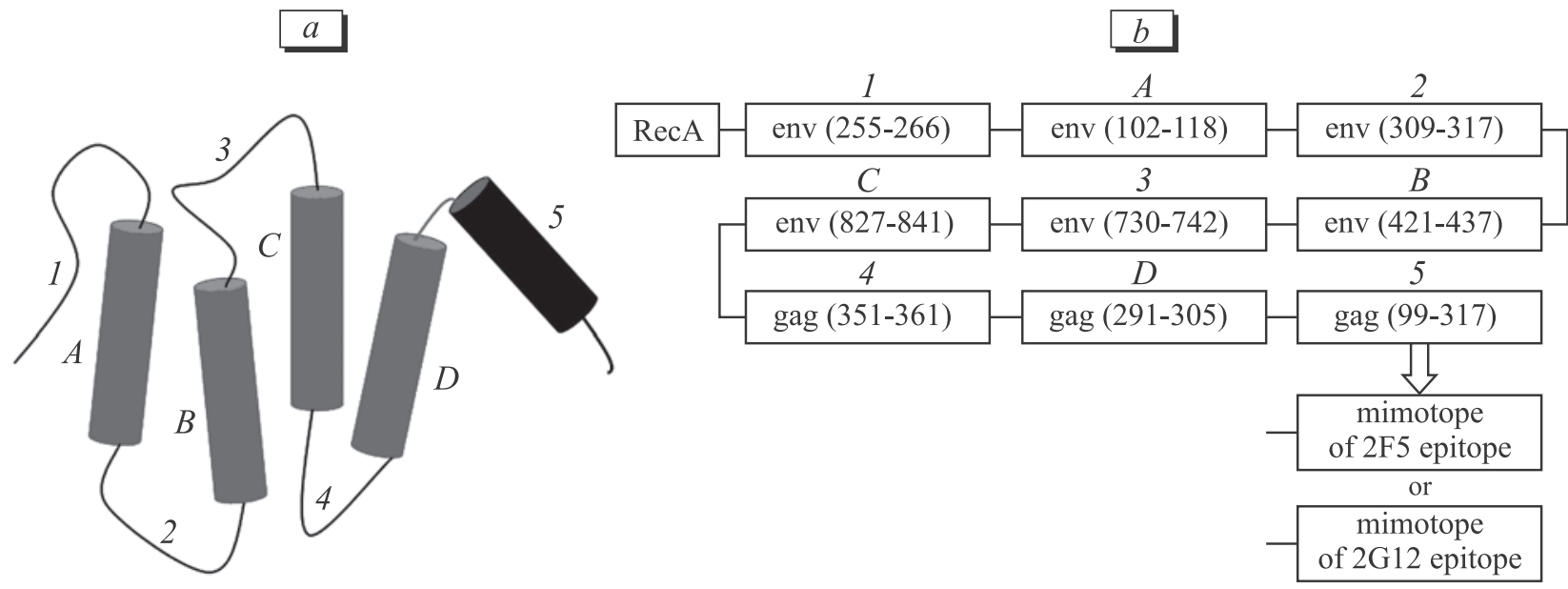

Fig. 1. Structure of multiepitope immunogenes TBI, TBI-2F5, and TBI-2G12. 1-5: B-cell epitopes of HIV-1. A-D: T-helper epitopes of HIV-1. a) ALB-modeled secondary structure of TBI [4]. b) Epitope location in TBI, TBI-2F5, and TBI-2G12. 


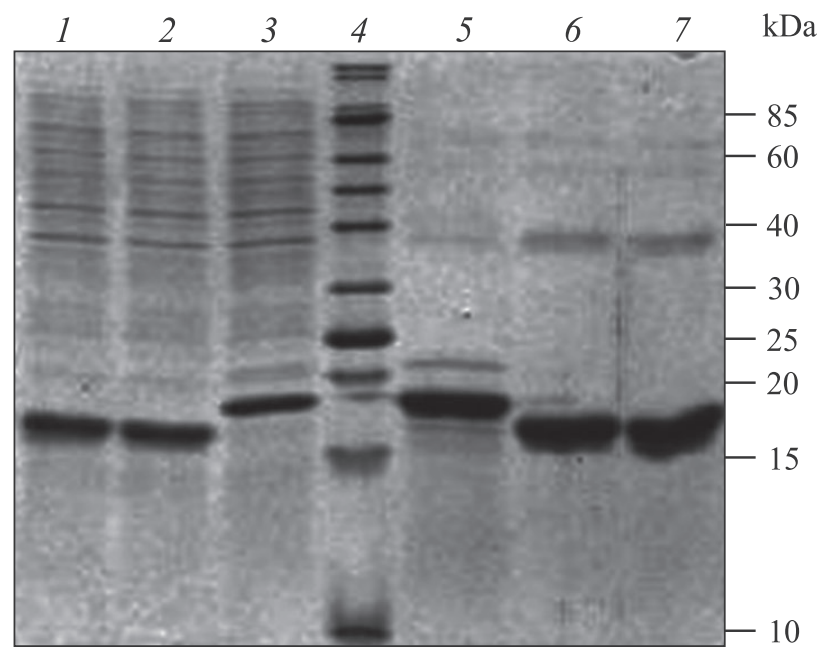

Fig. 2. Electrophoresis of E.coli JM103 lysates in 15\% SDS-PAAG. 1) E coli JM103/pTBI-2F5; 2) E. coli JM103/pTBI-2G12; 3) E. coli JM103/pTBI; 4) molecular weight marker M35 (SibEnzyme); 5) purified TBI; 6) purified TBI-2F5; 7) purified TBI-2G12.

TABLE 1. Neutralization of pseudoviruses with immune sera $(\%)$

\begin{tabular}{l|c|c}
\hline \multirow{2}{*}{\multicolumn{1}{c}{ Immunogen }} & \multicolumn{2}{c}{ Pseudovirus } \\
\cline { 2 - 3 } & QH0692.42 & PVO.4 \\
\hline TBI-2G12 & $25.6(25.3-25.8)$ & $17(16.3-17.8)$ \\
TBI-2F5 & $34.4(29.0-40.1)$ & $27.9(27.4-28.5)$ \\
TBI-2G12+TBI-2F5 & $46.5(45.3-47.6)$ & $41.6(37.0-46.7)$ \\
\hline
\end{tabular}

mice immunized with TBI-2F5 protein showed more efficient neutralization of tier 3 pseudovirus PVO.4 in comparison with the sera from mice immunized with TBI-2G12 and TBI (by 57 and 75\%, respectively). Moreover, the sera from mice immunized with proteins TBI and TBI-2F5 effectively neutralized pseu- doviruses CRF63 02A1 constructed at the Department of Bioengineering, State Research Center of Virology and Biotechnology Vector.

We also evaluated neutralizing activity of pooled sera from mice immunized with TBI-2F5 and TBI2G12 immunogens. Neutralization assay performed with two subtype B pseudoviruses, QH0692.42 and PVO.4 (Table 1). showed increased neutralizing activity of pooled sera (Table 1). This can suggest cooperative activity of antibodies, which is not unique. Cooperative activity was also demonstrated for $\mathrm{mAb}$ $2 \mathrm{~F} 5$ and 2 G12. Passive immunization with a mixture of $2 \mathrm{~F} 5,2 \mathrm{G} 12$, and polyclonal serum in one experiment $[7,9]$ and a mixture of antibodies $2 \mathrm{~F} 5,2 \mathrm{G} 12$, and F105 in the other $[1,13]$ protected macaques rhesus against infection with chimera simian-human immunodeficiency virus (SHIV) at different administration routes, while individual antibodies did not protect the animals. In contrast to individual antibodies, the mixture of $2 \mathrm{~F} 5,2 \mathrm{G} 12$, and $4 \mathrm{E} 10$ fully protected neonate macaques rhesus against oral SHIV89.6P challenge [4]. Another experiment showed that administration of 2F5 and 4E10 completely protected 5 of 6 macaques rhesus against mucosal SHIV challenge and one monkey demonstrated low viremia [5].

A possible mechanism of cooperative action of the sera from animals immunized with TBI-2G12 and TBI-2F5 is a conformational changes of env-pseudoviruse surface proteins during interaction with antibodies. Conformational changes of the surface proteins of pseudovirus induced by interaction with anti-TBI2G12 opened binding sites for TBI-2F5, which can provide more efficient viral neutralization.

Our study showed that antibodies in the serum of mice immunized with TBI-2G12 and TBI-2F5 exhibited neutralizing activity against tier 2 and 3 HIV-1 pseudoviruses. Pooled sera showed increased neutral-

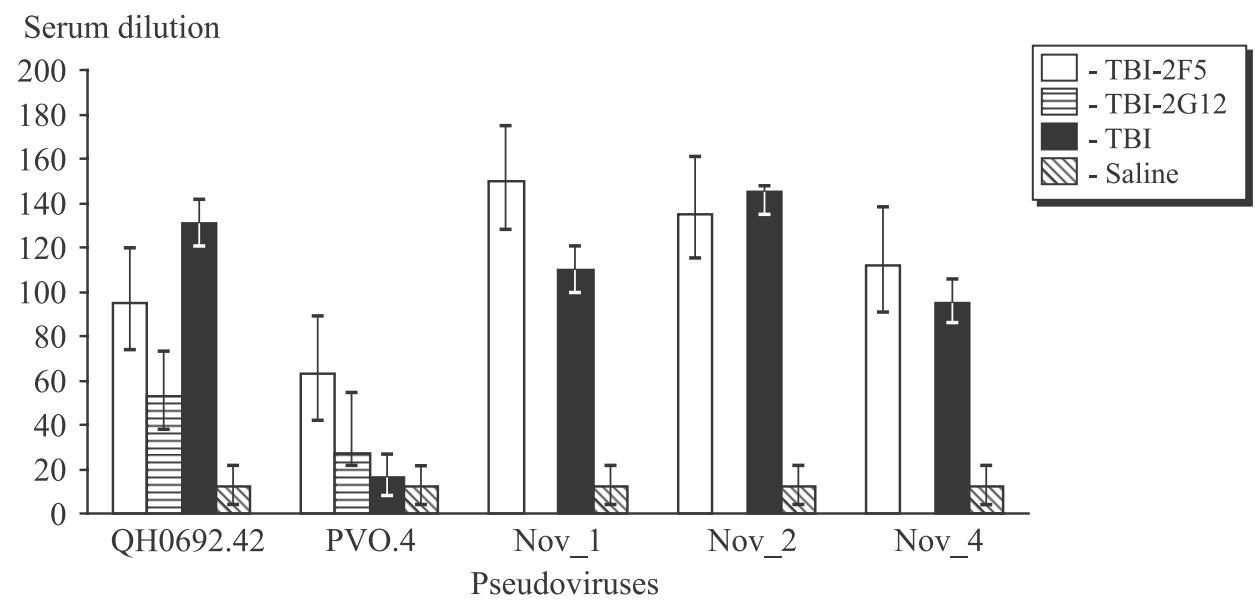

Fig. 3. Neutralization of pseudoviruses by sera from mice immunized with recombinant proteins TBI-2F5, TBI-2G12, and TBI. The results are presented as the mean of reciprocal titer corresponding $50 \%$ neutralization. 
izing activity. The observed result confirms the necessity of constructing immunogens that could present maximum numbers of epitopes, the targets of broadly neutralizing antibodies.

\section{REFERENCES}

1. Baba TW, Liska V, Hofmann-Lehmann R, Vlasak J, Xu W, Ayehunie S, Cavacini LA, Posner MR, Katinger H, Stiegler G, Bernacky BJ, Rizvi TA, Schmidt R, Hill LR, Keeling ME, Lu Y, Wright JE, Chou TC, Ruprecht RM. Human neutralizing monoclonal antibodies of the IgG1 subtype protect against mucosal simian-human immunodeficiency virus infection. Nat. Med. 2000;6(2):200-206.

2. Boutwell CL, Rolland MM, Herbeck JT, Mullins JI, Allen TM. Viral evolution and escape during acute HIV-1 infection. J. infect. Dis. 2010;202(Suppl. 2):S309-S314.

3. Eroshkin AM, Karginova EA, Gileva IP, Lomakin AS, Lebedev LR, Kamyinina TP, Pereboev AV, Ignat'ev GM. Design of four-helix bundle protein as a candidate for HIV vaccine. Prot. Eng. 1995;8(2):167-173.

4. Ferrantelli F, Rasmussen RA, Buckley KA, Li PL, Wang T, Montefiori DC, Katinger H, Stiegler G, Anderson DC, McClure HM, Ruprecht RM. Complete protection of neonatal rhesus macaques against oral exposure to pathogenic simianhuman immunodeficiency virus by human anti-HIV monoclonal antibodies. J. Infect. Dis. 2004;189(12):2167-2173.

5. Hessell AJ, Rakasz EG, Tehrani DM, Huber M, Weisgrau KL, Landucci G, Forthal DN, Koff WC, Poignard P, Watkins DI, Burton DR. Broadly neutralizing monoclonal antibodies 2F5 and 4E10 directed against the human immunodeficiency virus type 1 gp41 membrane-proximal external region protect against mucosal challenge by simian-human immunodeficiency virus SHIVBa-L. J. Virol. 2010;84(3):1302-1313.

6. Karpenko LI, Scherbakova NS, Chikaev AN, Tumanova OY, Lebedev LR, Shalamova LA, Pyankova OG, Ryzhikov AB, Ilyichev AA. Polyepitope protein incorporated the HIV-1 mi- motope recognized by monoclonal antibody $2 \mathrm{G} 12$. Mol. Immunol. 2012;50(4):193-199.

7. Mascola JR, Lewis MG, Stiegler G, Harris D, VanCott TC, Hayes D, Louder MK, Brown CR, Sapan CV, Frankel SS, Lu Y, Robb ML, Katinger H, Birx DL. Protection of Macaques against pathogenic simian/human immunodeficiency virus $89.6 \mathrm{PD}$ by passive transfer of neutralizing antibodies. J. Virol. 1999;73(5):4009-4018.

8. Mascola JR, Montefiori DC. The role of antibodies in HIV vaccines. Annu. Rev. Immunol. 2010;28:413-444.

9. Mascola JR, Stiegler G, VanCott TC, Katinger H, Carpenter CB, Hanson CE, Beary H, Hayes D, Frankel SS, Birx DL, Lewis MG. Protection of macaques against vaginal transmission of a pathogenic HIV-1/SIV chimeric virus by passive infusion of neutralizing antibodies. Nat. Med. 2000;6(2):207210.

10. Scanlan CN, Pantophlet R, Wormald MR, Ollmann Saphire E, Stanfield R, Wilson IA, Katinger H, Dwek RA, Rudd PM, Burton DR. The broadly neutralizing anti-human immunodeficiency virus type 1 antibody $2 \mathrm{G} 12$ recognizes a cluster of alpha1 $\rightarrow 2$ mannose residues on the outer face of gp120. J. Virol. 2002;76(14):7306-7321.

11. Shcherbakova NS, Shcherbakov DN, Bakulina AY, Karpenko LI, Ryzhikov AB, Ilyichev AA. Artificial polyepitope HIV-1 immunogen containing mimotope of 2F5 epitope. Protein Pept. Lett. 2016;23(2):159-168.

12. Smith GP, Petrenko VA. Phage display. Chem. Rev. 1997;97(2): 391-410.

13. Xu W, Hofmann-Lehmann R, McClure HM, Ruprecht RM. Passive immunization with human neutralizing monoclonal antibodies: correlates of protective immunity against HIV. Vaccine. 2002;20(15):1956-1960.

14. Zwick MB, Jensen R, Church S, Wang M, Stiegler G, Kunert R, Katinger H, Burton DR. Anti-human immunodeficiency virus type 1 (HIV-1) antibodies $2 \mathrm{~F} 5$ and $4 \mathrm{E} 10$ require surprisingly few crucial residues in the membrane-proximal external region of glycoprotein gp41 to neutralize HIV-1. J. Virol. 2005;79(2):1252-1261. 